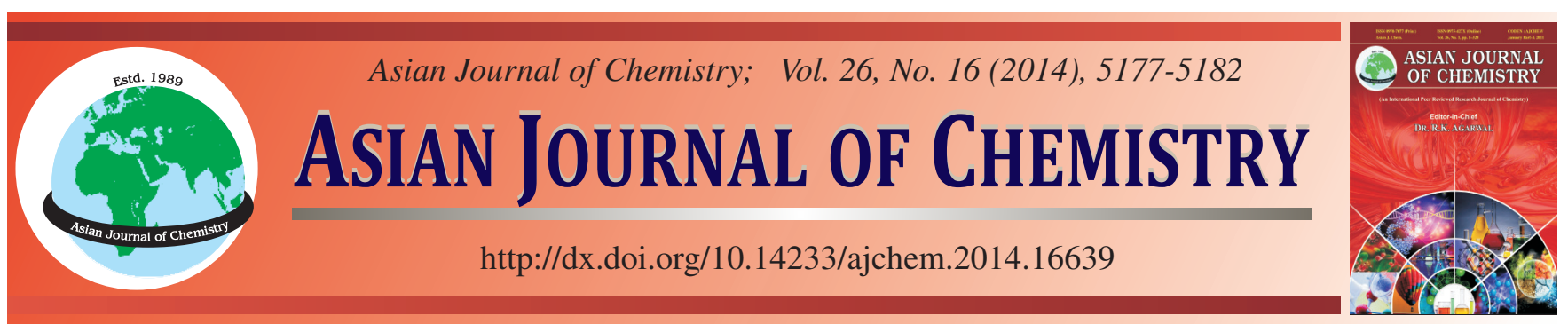

\title{
Pretreatment of Brine Generated from Desalination Process for its Reclamation by Bipolar Membrane Electrodialysis
}

\author{
K.K. $\mathrm{WANG}^{1}$, M. $\mathrm{WANG}^{1, *}$, P.F. ZHOU ${ }^{1}$ and Q.C. REN ${ }^{2}$
}

${ }^{1}$ College of Chemistry and Chemical Engineering, Ocean University of China, Qingdao 266100, P.R. China

${ }^{2}$ Beijing Unisplendour Empyreal Environmental Engineering Technology Co. Ltd, Beijing 100083, P.R. China

*Corresponding author: Tel: +86 532 66786513; E-mail: wangmeng@ ouc.edu.cn

Due to the exact demands of bipolar membrane electrodialysis (BMED) on water quality, an effective pretreatment for the effluents from desalination processes is one of the most important tasks for putting the bipolar membrane electrodialysis reclamation technology into practical use. In this study, an enhanced softening method in which the $\mathrm{Na}_{2} \mathrm{CO}_{3}-\mathrm{NaOH}$ softening and polyaluminium chloride coagulation were combined was attempted. Series of experiments designed by Response surface methodology (RSM) were conducted for exploring the relationships between the removal rate of the contaminants and the relevant independent variables. Based on the obtained models, an optimum scheme can be achieved. At last, various kinds of typical domestic cation exchange resins were attempted for further reduction of the hardness and the relevant optimum operating conditions, such as resin type and flow rate of brine, were obtained.

Keywords: Enhanced softening method, Electrodialysis, Brine reclamation, Polyaluminum chloride, Response surface methodology.

ᄂ - - - - - - - - - - - - - - - - - - - - - - - - - - -

\section{INTRODUCTION}

Nowadays, the special importance of desalination of seawater, brackish groundwater and surface water in increasing freshwater supply has been widely recognized ${ }^{1}$. The global water production by desalination will be projected to exceed 38 billion $\mathrm{m}^{3}$ per year in 2016 , twice the rate of that in $2008^{2}$. It is self-evident that, whether from economical or environmental points of views, the issue of concentrate management is becoming an increasing challenge, especially for inland desalination plants ${ }^{3}$. Accordingly, some technical schemes, including thermal, membrane-based and other techniques, have been designed for brine volume minimization, which have been reviewed by Bruggen et al. ${ }^{4}$. Among them, some notable examples are electrodialysis-based hybrid processes for recovering product water and mineral byproducts from the brackish water ${ }^{5-8}$.

As a kind of derived technology of conventional electrodialysis, bipolar membrane electrodialysis can achieve the water splitting and salt dissociation at the same time by means of the ingenious combination of bipolar membranes and monopolar membranes so that the salt can be converted into the corresponding acid and alkali. As expected, bipolar membrane electrodialysis has also been tried to manage concentrates generated from some water desalination processes ${ }^{8-10}$. Although its feasibility has been confirmed many times by series of technological-economical analyses, these are not enough to put the bipolar membrane electrodialysis-based reclamation scheme for brine management into practice. One of the main reasons lies in the exact demands of bipolar membrane electrodialysis (BMED) on water quality. It is well known that the membrane fouling and scaling can remarkably deteriorate stability, effectivity and economy of electrodialysis process. Considering susceptibility of the anion exchange membrane and cation exchange membrane to the colloids and precipitates of calcium and magnesium ions, respectively, an effective pretreatment for the effluents from desalination processes must be performed before being fed into the bipolar membrane electrodialyzer.

Therefore, the pretreatment of brine for bipolar membrane electrodialysis was highlighted in this study. That is, an enhanced softening scheme combined with coagulation was designed. Therein, response surface methodology (RSM) method was employed to explore the interactions among the operating conditions and analyze their contributions to the removal of hardness, silica and organic matter, especially for that of coagulants. Based on the above experiments, an optimized pretreatment scheme can be obtained.

\section{EXPERIMENTAL}

Water quality: The brine sample was taken from a chemical plant located in Shanghai in which the Yangtse River's water was desalinated to supply production water. Some typical water quality parameters were included in Table-1. 
Pretreatment experiments: An option procedure of the enhanced softening process was as follows. Above all, a titration curve of the raw water $(250 \mathrm{~mL})$ in which the stoichiometrically predetermined $\mathrm{Na}_{2} \mathrm{CO}_{3}$ was added was obtained to grasp the change of system $\mathrm{pH}$ with the dosage of $\mathrm{NaOH}$. In order to reduce the influence of titrant on the solution volume as far as possible, a concentrated solution of sodium hydroxide (e.g. $1 \mathrm{~mol} / \mathrm{L})$ was used. Then, series of jar tests were performed under different operating conditions. Firstly, the predetermined $\mathrm{Na}_{2} \mathrm{CO}_{3}$ and $\mathrm{NaOH}$ were added into $1 \mathrm{~L}$ raw water at the same time along with a rapid mixing. After $15 \mathrm{~s}$, the predetermined polyaluminum chloride ( $\mathrm{PACl})\left(30 \% \mathrm{Al}_{2} \mathrm{O}_{3}\right.$ content, Beijing KPHW Technology Co., Ltd., China) was added and stirred with a speed of $250 \mathrm{rpm}$ for $2 \mathrm{~min}, 40 \mathrm{rpm}$ for $10 \mathrm{~min}$ and then $0.5 \mathrm{~h}$ of quiescent settling. Coagulants as well as $\mathrm{Na}_{2} \mathrm{CO}_{3}$ and $\mathrm{NaOH}$ were dosed using pipettes, which were calibrated before each experiment. After being filtered with a $0.45 \mu \mathrm{m}$ membrane, the treated water was stored in PE bottles for further analysis and subsequent treatment.

\begin{tabular}{ccc}
\multicolumn{3}{c}{ TABLE-1 } \\
\multicolumn{2}{c}{ WATER QUALITY OF BRINE INVESTIGATED } \\
\hline Parameters & Units & Brine \\
\hline $\mathrm{Na}^{+}$ & $\mathrm{mmol} / \mathrm{L}$ & 158.5 \\
$\mathrm{Ca}^{2+}$ & $\mathrm{mmol} / \mathrm{L}$ & 22.9 \\
$\mathrm{Mg}^{2+}$ & $\mathrm{mmol} / \mathrm{L}$ & 5.8 \\
Total alkalinity & $\mathrm{mmol} / \mathrm{L}$ & 1.8 \\
$\mathrm{SO}_{4}^{2-}$ & $\mathrm{mmol} / \mathrm{L}$ & 2.9 \\
$\mathrm{Cl}^{-}$ & $\mathrm{mmol} / \mathrm{L}$ & 222.5 \\
$\mathrm{SiO}_{2}$ & $\mathrm{mg} / \mathrm{L}$ & 67.153 \\
$\mathrm{pH}^{2+}$ & & 7.45 \\
Conductivity & $\mathrm{ms} / \mathrm{cm}$ & 20.4 \\
$\mathrm{UV}_{254}$ & & 1.512 \\
\hline
\end{tabular}

In this study, response surface methodology, an effective technique for exploring the relationships between the response and the independent variables and analyzing the interactions among the influencing factors, was employed to form an optimized pretreatment scheme. The experimental design and statistical analysis were carried out using Design-expert software version ${ }^{8}$. Especially, the Central Composite Design with a quadratic model was adopted to study the effects of independent variables. Moreover, analysis of variance (ANOVA) was also performed to evaluate the regressed models.

At last, four kinds of typical cation exchange resins which are products of Shanghai Huizhi resin factory (China), including D001 (macroporous strong acidic cation resin), D113 (macroporous weak acidic cation resin), 732 (gel-type strong acidic cation resin) and 110 (gel-type weak acidic cation resin), were attempted and compared for the further reduction of hardness.

Analysis: $\mathrm{UV}_{254}$, denoting the content of organic matter in brine, was measured by a spectrophotometer (UV-1600PC, Mapada) at a wavelength of $254 \mathrm{~nm}$ using a $1 \mathrm{~cm}$ quartz cell after being two times diluted. Soluble silica was measured using the silico-molybdate spectrophotometric method ${ }^{11}$. Some key ions, such as $\mathrm{Ca}^{2+}, \mathrm{Mg}^{2+}, \mathrm{SO}_{4}{ }^{2-}, \mathrm{Cl}^{-}$and total alkalinity, were analyzed by an automatic potentiometric titration instrument (ZD-2, Leici). Sodium ion analyzer (DWS-51, Leici) was employed to measure the concentration of $\mathrm{Na}^{+}$. In addition, Conductivity meter (DDSJ-308A, Leici) and pH meter (pHS$3 \mathrm{G}$, Leici) were used in this study, which were daily calibrated.

\section{RESULTS AND DISCUSSION}

Proposal for brine pretreatment: Generally speaking, in order to ensure a failure-free run of the desalination process in a long-term, a pretreatment has been conducted before being fed into RO or ED set-up. Accordingly, the purpose of brine pretreatment for the bipolar membrane electrodialysis -based reclamation process mainly lies in the decrease or even complete removal scalants for cation exchange membrane (in principle calcium and magnesium ions) and foulants particularly for anion exchange membrane (in principle silica and some residue organics). Due to its efficiency and economy, softening treatment of water was carried out mainly by the alkalization technology, including lime method, lime-soda ash $\left(\mathrm{Na}_{2} \mathrm{CO}_{3}\right)$ method and caustic soda $(\mathrm{NaOH})$ method. In view of its considerable merits in producing less sludge, precisely controlling alkalization, steady operation and self-sustaining because the required $\mathrm{NaOH}$ can be supplied by the subsequent bipolar membrane electrodialysis -based reclamation process itself, a modified caustic soda method will be employed in this proposal. In addition, some $\mathrm{Na}_{2} \mathrm{CO}_{3}$ were needed to supplement carbonates due to the relatively high ratio of calcium hardness and alkalinity of this brine (Table-1).

Silica scale formation is another serious problem during the water treatment process by membrane-based method because silica and/or silicate deposits are particularly difficult to be removed once they formed. Owing to the strong adsorption interactions between $\mathrm{Mg}(\mathrm{OH})_{2}$ and dissolved silica and the formation of $\mathrm{Mg}$-hydroxysilicates precipitates, silica removal can usually be carried out along with an appropriate softening process. Similarly, the removal of natural organic matter (NOM) can also be achieved during the softening process due to the adsorption of natural organic matter on the precipitates. Accordingly, an improved scheme for the pretreatment of brine, the so-called enhanced softening methods, was designed in this study, including some cationic polyelectrolyte for altering the surface character of $\mathrm{CaCO}_{3}$ precipitates and facilitating the formation of $\mathrm{Mg}(\mathrm{OH})_{2}$ precipitates. In view of the important roles in the removal of natural organic matter and silica played by precipitation of calcium and magnesium, it is necessary to grasp the relevant influencing factors and optimize the operational conditions for precipitation process.

Influence of system $\mathrm{pH}$ on the removal of hardness, $\mathrm{Si}$ and the organics: Fig. 1 demonstrated the change of system $\mathrm{pH}$ along with the addition of a concentrated solution of sodium hydroxide. First, it can be seen that the solution system became alkaline after the addition of $2 \mathrm{~g} / \mathrm{L} \mathrm{Na}_{2} \mathrm{CO}_{3}$ for supplementing carbonates. Furthermore, it is noticed that two "pseudo-plateau" appeared on the titration curve with the addition of sodium hydroxide. Obviously, the presence of a strong buffering effect characteristic should be attributed to the formation of $\mathrm{CaCO}_{3}$ and $\mathrm{Mg}(\mathrm{OH})_{2}$ precipitates. The titration curve can help to grasp the optimized $\mathrm{pH}$ ranges for carbonate precipitation and magnesium hydroxide deposition. That is, for the system, the alteration of bicarbonate to carbonate precipitation started at 


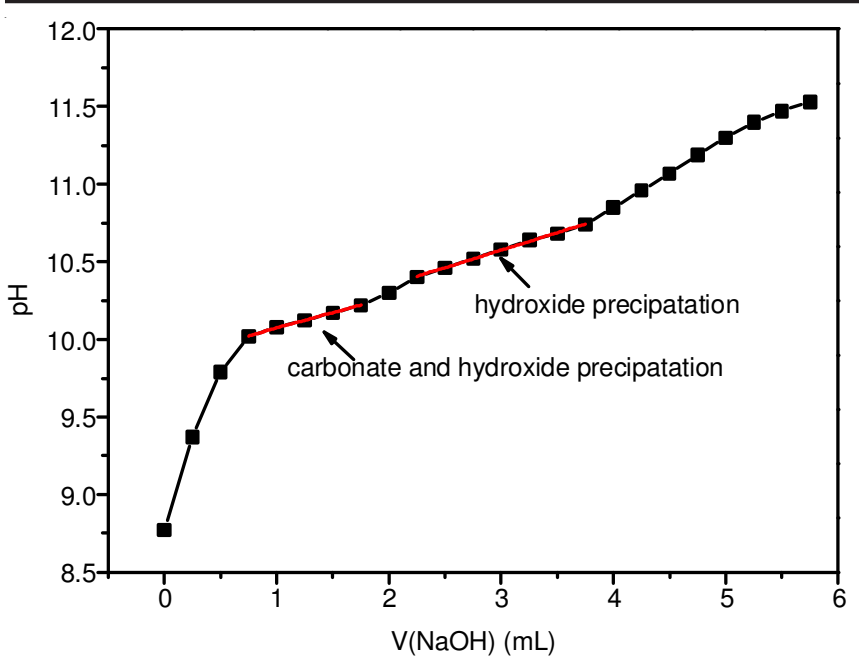

Fig. 1. Titration curve of the raw water in which the stoichiometrically predetermined

about $\mathrm{pH}$ 10, while magnesium hydroxide deposition completed at about $\mathrm{pH} 10.8$.

In order to meet the requirements of different water quality, it is necessary to discern the contributions of calcium removal and magnesium removal, respectively, to the removal of organic matter and $\mathrm{Si}$ after the addition of polyaluminium chloride. Because only $2 \mathrm{~g} / \mathrm{L} \mathrm{Na}_{2} \mathrm{CO}_{3}$, but no $\mathrm{NaOH}$, was added during the experiments described by Fig. 2, the hardness removal was mainly denoted as Calcium removal. Above all, it can be noticed that the removal of calcium hardness was almost independent of the addition of polyaluminium chloride, but the case for removal of organic matter and Si removal were greatly different. It can be seen clearly the removal of organic matter can be improved with the increase of dosage of polyaluminium chloride. This should be attributed to the achievement of positively-charged surface of calcium carbonate after adding cationic polyaluminium chloride which contributed to the adsorption of negatively-charged organic matter on them. And, the increasing amplitude is not as large as the expected. This may be related to the dense crystalline structure of calcium carbonate. However, just as displayed in Fig. 2, the addition of polyaluminium chloride can significantly interfere with $\mathrm{Si}$

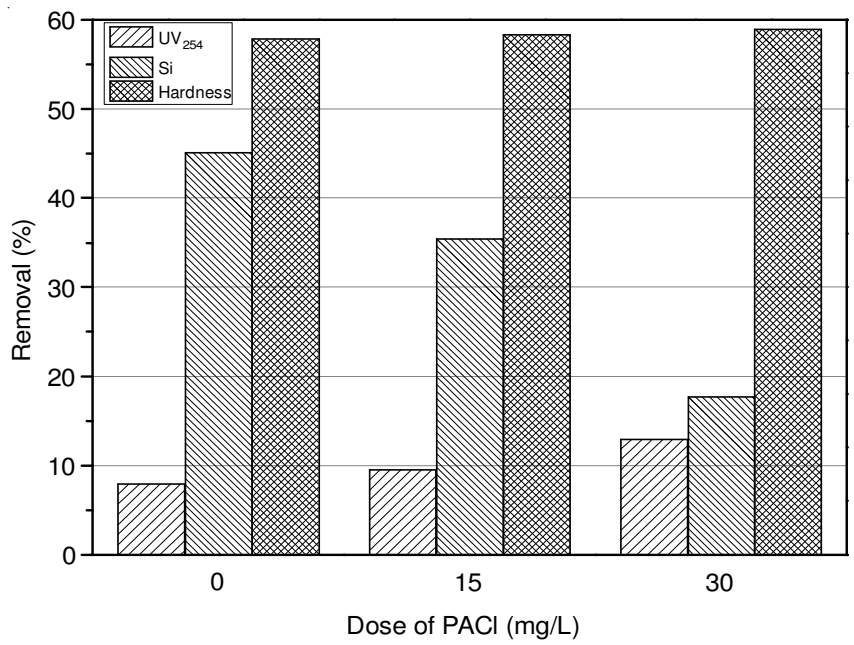

Fig. 2. Effect of polyaluminium chloride dosage on the removal of $\mathrm{UV}_{254}$, $\mathrm{Si}$ and hardness. $\left(\mathrm{Na}_{2} \mathrm{CO}_{3}: 2 \mathrm{~g} / \mathrm{L} ; \mathrm{pH}=9\right)$ removal. This indicated that the cationic polyaluminium chloride seemed to serve as the inhibitor or dispersion agent for negatively charged silicate anions or $\mathrm{SiO}_{2}$ particles when being added into the brine. Thus, the formation and attachment of colloidal silica were hindered to a large extent.

As a comparison, the above experiments were performed again at $\mathrm{pH}$ around ${ }^{10}$. Obviously, under these circumstances, magnesium precipitates will also start. Fig. 3 that the removal of $\mathrm{Si}$ and organic matter were improved significantly. This indicated that magnesium precipitates played more important roles in the removal of $\mathrm{Si}$ and organic matter. Obviously, all these should be attributed to the amorphous structure, large surface area and positively-charged surface of magnesium hydroxide precipitates. That is why the removal of organic matter seemed to be independent of the addition of polyaluminium chloride, which is different from the case of calcium precipitates mentioned above. In addition, it was worth noting that the influence of polyaluminium chloride addition on the Si removal took on completely different tendencies before and after the occurrence of magnesium hydroxide precipitates. That is, the formation of aluminum, magnesium and silicon compounds at relatively high $\mathrm{pH}$ (for example, $\mathrm{pH}>10$ ) will make a significant contribution to $\mathrm{Si}$ removal. For example, the removal rate can reach as high as about $90 \%$ in some experiments.

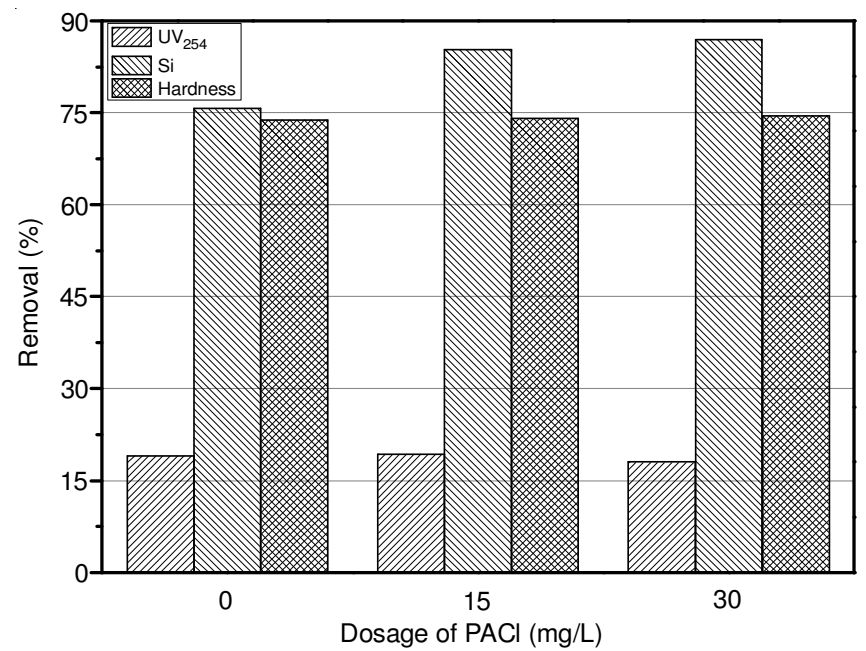

Fig. 3. Effect of polyaluminium chloride dosage on the removal of $\mathrm{UV}_{254}$, $\mathrm{Si}$ and hardness. $\left(\mathrm{Na}_{2} \mathrm{CO}_{3}: 2 \mathrm{~g} / \mathrm{L} ; \mathrm{pH}=10\right)$

Optimization of pretreatment scheme by response surface methodology: As can be seen from above experiments, it is very necessary to comprehensively explore the relationships between the removal of $\mathrm{Si}$, organic matter and hardenss and the independent variables, including the system $\mathrm{pH}$ and the dose of polyaluminium chloride and analyze the interactions among the influencing factors. Furthermore, an optimized pretreatment scheme can be obtained. Hence, series of experiments were designed and analyzed by response surface methodology. The low, middle and high levels of each variable was designated as $-1.414,-1,0,1$ and 1.414 , respectively, which were shown in Table-2. Thirteen experiments were performed at different combinations of the above factors and the experimental results were summarized in Table- 3 . 


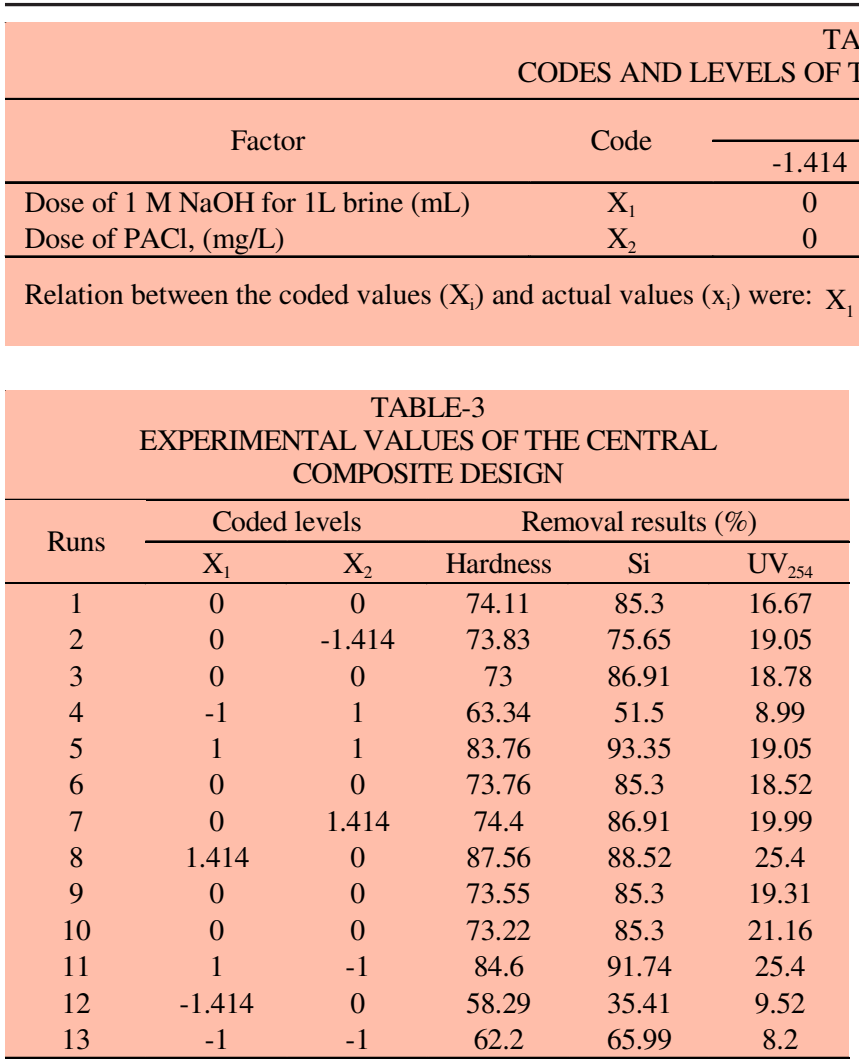

Model fitting: Regression analysis and ANOVA were used to fit the models and examine the statistical significance of the model terms. The yielded regression equations which were fitted by the second-order response surface model and summarized in Table-4 demonstrated the relationship between the removal of hardness, $\mathrm{Si}$ and the organics and the test variables. Furthermore, the F-test was applied to check the statistical significance of the above regression equations. As can also be seen from Table-3, the high values of $\mathrm{F}$ and the very low probability value indicated the high significance of the fitted model.

In addition, the analysis of variance was also performed to achieve the determination coefficient $\left(R^{2}\right)$, the adjusted determination coefficient $\left(\mathrm{R}_{\text {adj }}^{2}\right)$ and the coefficient of variation (C.V. \%), which can be used to evaluate the fit of the obtained regression models. Generally speaking, value, a measure of the variability in the observed response values, higher than 0.90 indicates the obtained regression model has a very high correlation $^{12}$. Moreover, the closer the value is to unity, the better the model fit the experimental data and the smaller the difference between the predicted and observed values ${ }^{13}$. In addition, a low value of also indicates the reliability of the fitted mode ${ }^{14}$. Accordingly, it is reasonable to think that the regressive models fitted in this study, especially for the removal of hardness and Si, embraced a high level of significance and accuracy.

ABLE-2

THE EXPERIMENTAL DESIGN 
$\mathrm{mL}$ (for the $1 \mathrm{~L}$ brine, system $\mathrm{pH}$ is about 10.8) and 16.80 $\mathrm{mg} / \mathrm{L}$, respectively. Under the optimum conditions, the removal of hardness, Si and organics can reach 84, 93.35 and $23.82 \%$, respectively. Furthermore, an additional verifying experiment was carried out after the dosage of $\mathrm{Na}_{2} \mathrm{CO}_{3}$ was adjusted based on the total alkalinity of the brine. The results showed that the content of the $\mathrm{Si}$ and hardness in the treating water were about only $3.75 \mathrm{mg} / \mathrm{L}$ and $1.9656 \mathrm{mmol} / \mathrm{L}$ (including $\mathrm{Ca}=65.52$ $\mathrm{mg} / \mathrm{L}$ and $\mathrm{Mg}=7.8624 \mathrm{mg} / \mathrm{L})$, respectively. Obviously, some further treatments were needed before being fed into the bipolar membrane electrodialyzer.

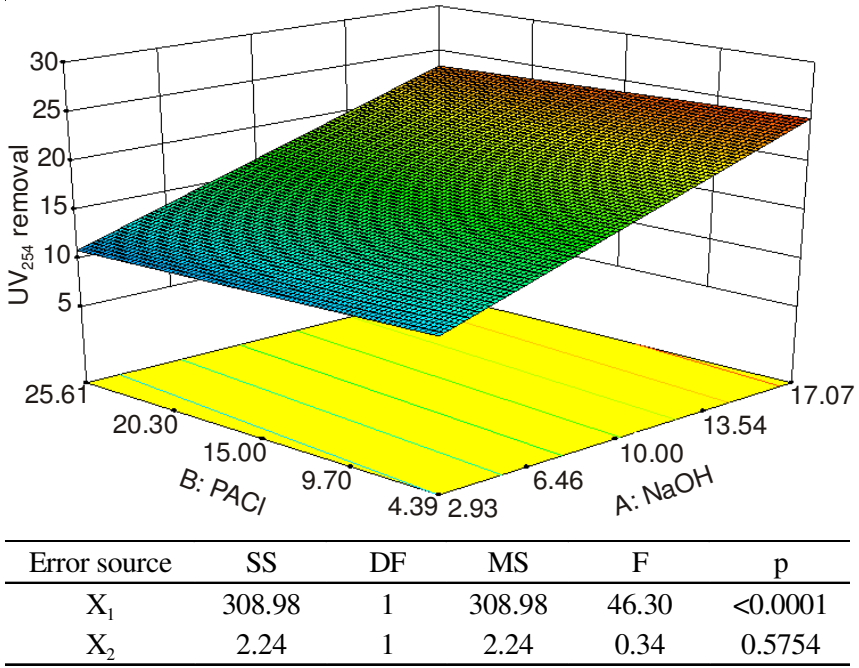

$\mathrm{SS}$, sum of squares; DF, degree of freedom; MS, mean square

Fig. 5. Effects of polyaluminium chloride and $\mathrm{NaOH}$ on organics removal

Profound treatment for the brine: Generally speaking, for bipolar membrane electrodialysis, the content of the divalent cations in feed solutions should not exceed 1-2 ppm, otherwise the metallic hydroxides will precipitate in the membranes ${ }^{16,17}$. In this work, four kinds of typical domestic cation exchange resins were attempted for further reduction of the hardness. As can be seen from Table-5, D001-form, a kind of macroporous strong acidic cation resin, can efficiently reduce metal contaminants in its recommending range of flow rate. Further results showed that the $\mathrm{pH}$ of the brine pretreated by the above enhanced softening method can remain about 10.8 during the entire process of the ion exchange because of the adoption of Na-form resins. Besides, the resins can be regenerated conveniently in the form of counter-current with $\mathrm{HCl}$ and $\mathrm{NaOH}$ produced by subsequent bipolar membrane electrodialysis stage. Of course, the operational time between regenerations will solely depend on the residual hardness after $\mathrm{Na}_{2} \mathrm{CO}_{3}-\mathrm{NaOH}$ softening. In addition, removal of $\mathrm{Si}$ is usually

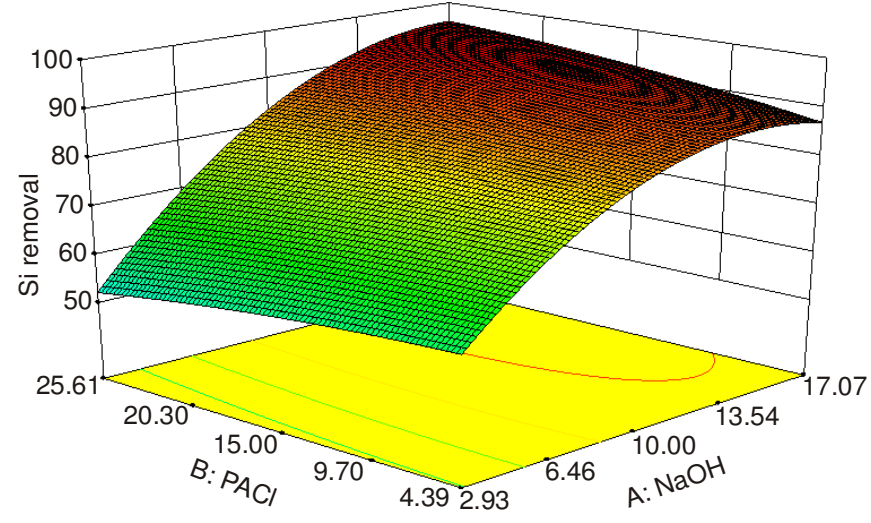

\begin{tabular}{cccccc}
\hline $\begin{array}{c}\text { Error } \\
\text { source }\end{array}$ & $\mathrm{SS}$ & $\mathrm{DF}$ & $\mathrm{MS}$ & $\mathrm{F}$ & $\mathrm{p}$ \\
\hline $\mathrm{X}_{1}$ & 2545.73 & 1 & 2545.73 & 122.73 & $<0.0001$ \\
$\mathrm{X}_{2}$ & 1.16 & 1 & 1.16 & 0.056 & 0.8200 \\
\hline $\mathrm{X}_{1} \mathrm{X}_{2}$ & 64.80 & 1 & 64.80 & 3.12 & 0.1205 \\
\hline $\mathrm{X}_{1}{ }^{2}$ & 814.85 & 1 & 814.85 & 39.29 & 0.0004 \\
\hline $\mathrm{X}_{2}{ }^{2}$ & 9.45 & 1 & 9.45 & 0.46 & 0.5214 \\
\hline
\end{tabular}

$\mathrm{SS}$, sum of squares; DF, degree of freedom; MS, mean square

Fig. 6. Effects of polyaluminium chloride and $\mathrm{NaOH}$ on $\mathrm{Si}$ removal

another concern because the Si scale on the membrane is hard to be removed once they formed. Mavrov et. al. ${ }^{9}$ adjusted the $\mathrm{pH}$ of the feed solution from about 11 to 2 for the removal of silica precipitates and the adsorptive substances on it. Obviously, this consume large amount of $\mathrm{HCl}$. In our case, a softening method combined with polyaluminium chloride coagulation was employed and a high Si removal rate can be achieved. Just as expected, the bipolar membrane electrodialysis experiments lasting for a long time has proved that the fouling and scaling of anion exchange membrane were insignificant.

\section{Conclusions}

Before putting the bipolar membrane electrodialysis-based reclamation scheme for brine produced during the desalination process into service, an effective pretreatment method for brine must be achieved. In view of the characteristics of the reclamation process, an enhanced softening scheme which combined the $\mathrm{Na}_{2} \mathrm{CO}_{3}-\mathrm{NaOH}$ softening method with polyaluminium chloride coagulation was attempted in this study. In the optimum $\mathrm{pH}$ ranges for the removal of calcium hardness, the influence of polyaluminium chloride addition on the removal of organic matter and Si removal were greatly different. That is, with the increase of dosage of polyaluminium chloride, the removal of organic matter can be improved due to the endowment of positively-charged surface to calcium carbonate after being modified by cationic polyaluminium chloride, whereas the Si removal was impeded because the cationic

TABLE-5

PERFORMANCE OF TYPICAL CATION RESINS FOR FURTHER HARDNESS REMOVAL

\begin{tabular}{lcc|cc|cc|cc}
\hline Cation Resin & \multicolumn{2}{c|}{ D113-Type } & \multicolumn{2}{c|}{ 732-Type } & \multicolumn{2}{c|}{ 110-Type } & \multicolumn{2}{c}{ D001-Type } \\
\hline Flow rate, $(\mathrm{m} / \mathrm{h})$ & 20 & 25 & 20 & 25 & 20 & 25 & 20 & 25 \\
Flow rate, $(\mathrm{m} / \mathrm{h})$ & 20 & 25 & 20 & 25 & 20 & 25 & 20 & 25 \\
$\mathrm{Ca},(\mathrm{mg} / \mathrm{L})$ & 0.208 & 0.416 & 0.104 & 0.312 & 0.52 & 0.624 & U.D.L. & 0.104 \\
$\mathrm{Mg},(\mathrm{mg} / \mathrm{L})$ & 2.022 & 2.546 & 2.558 & 3.682 & 2.134 & 2.621 & 0.374 & 0.811 \\
Removal rate, $(\%)$ & 96.96 & 95.96 & 96.37 & 94.56 & 96.08 & 95.20 & 99.45 & 98.65 \\
\hline
\end{tabular}


polyaluminium chloride seemed to serve as the inhibitor or dispersion agent for negatively charged silicate anions or $\mathrm{SiO}_{2}$ particles. In addition, the removal of calcium hardness was almost independent of the addition of polyaluminium chloride.

Furthermore, series of experiments in wide $\mathrm{pH}$ range designed by response surface methodology showed that the system $\mathrm{pH}$ is the most significant factor for affecting the removal of hardness, $\mathrm{Si}$ and organics, whereas the dosage of polyaluminium chloride has a very minor influence on them. Of course, the addition of polyaluminium chloride seemed to play some roles in Si removal, which should be related to the formation of aluminum, magnesium and silicon compounds at relatively high $\mathrm{pH}$ besides the adsorption of negativelycharged silicate anions on positively-charged magnesium hydroxide precipitates. After a comprehensive consideration, the optimized $\mathrm{pH}$ (10.8) and the optimized dosage of polyaluminium chloride $(16.80 \mathrm{mg} / \mathrm{L})$ were achieved. An additional verifying experiment was carried out after the dosage of $\mathrm{Na}_{2} \mathrm{CO}_{3}$ was adjusted based on the total alkalinity of the brine and the content of the $\mathrm{Si}$ and hardness in the treating water were about $3.75 \mathrm{mg} / \mathrm{L}$ and $1.9656 \mathrm{mmol} / \mathrm{L}$ (including $\mathrm{Ca}=$ $65.52 \mathrm{mg} / \mathrm{L}$ and $\mathrm{Mg}=7.8624 \mathrm{mg} / \mathrm{L}$ ), respectively.

At last, various kinds of typical domestic cation exchange resins were attempted for further reduction of the hardness. Series of experiments indicated that D001-form, a kind of macroporous strong acidic cation resin, can efficiently reduce metal contaminants in its recommending range of flow rate.

\section{ACKNOWLEDGEMENTS}

This research is supported in part by the National Science foundation of China (No. 21276245) and Natural Science Foundation of Shandong Province (ZR2011EMQ004).

\section{REFERENCES}

1. M.A. Shannon, P.W. Bohn, M. Elimelech, J.G. Georgiadis, B.J. Mariñas and A.M. Mayes, Nature, 452, 301 (2008).

2. Q. Schiermeier, Nature, 452, 260 (2008).

3. M. Elimelech and W.A. Phillip, Science, 333, 712 (2011).

4. B. Van der Bruggen, L. Lejon and C. Vandecasteele, Environ. Sci. Technol., 37, 3733 (2003).

5. Y. Oren, E. Korngold, N. Daltrophe, R. Messalem, Y. Volkman, L. Aronov, M. Weismann, N. Bouriakov, P. Glueckstern and J. Gilron, Desalination, 261, 321 (2010).

6. Y. Tanaka, R. Ehara, S. Itoi and T. Goto, J. Membr. Sci., 222, 71 (2003).

7. Y. Zhang, K. Ghyselbrecht, R. Vanherpe, B. Meesschaert, L. Pinoy and B. Van der Bruggen, J. Environ. Manag., 107, 28 (2012).

8. M. Badruzzaman, J. Oppenheimer, S. Adham and M. Kumar, J. Membr. Sci., 326, 392 (2009).

9. V. Mavrov, H. Chmiel, B. Heitele and F. Rögener, Desalination, 124, 205 (1999).

10. R. Ibáñez, A. Pérez-González, P. Gómez, A.M. Urtiaga and I. Ortiz, Desalination, 309, 165 (2013).

11. Determination of Silica (Dissolved) (Molybdosilicate Method), Chinese Standard: SL 91.1-1994, The Ministry of Water Resources of Peoples' Republic of China.

12. P.D. Haaland, Experimental Design in Biotechnology, Marcel Dekker, New York (1989).

13. F. Karacan, U. Ozden and S. Karacan, Appl. Therm. Eng., 27, 1212 (2007).

14. Y.M. Wang, C.H. Huang and T.W. Xu, J. Membr. Sci., 362, 249 (2010).

15. M.Q. Yan, D.S. Wang, J.R. Ni, J.H. Qu, Y. Yan and C.W.K. Chow, Sep. Purif. Technol., 62, 401 (2008).

16. G. Pourcelly and C. Gavach, in ed.: A.J.B. Kemperman, Electrodialysis Water Splitting -Applications of Electrodialysis with Bipolar Membranes (EDBM), In: Handbook on Bipolar Membrane Technology, Twente University Press, Enschede, The Netherlands, pp. 17-46 (2000).

17. K.N. Mani, J. Membr. Sci., 58, 117 (1991). 